\title{
Computer models for maximizing tumor cell kill and for minimizing side effects in radiation therapy
}

\author{
W. Düchting and T. Ginsberg
}

Department of Electrical Engineering and Computer Science

University of Siegen, 57068 Siegen, Germany.

Tel: 0271/740-4437. Fax: 0271/740-4382.

e-mail: duechtingehrz . uni-siegen.d400.de

$W$. Ulmer

Max-Planck-Institute of Biophysical, 37073 Göttingen, Germany.

\begin{abstract}
Previous studies have shown that systems analysis, control theory and computer science can stimulate new approaches to interpret cancer as an unstable closed-loop control circuit, to study tumor growth, and to optimize tumor treatment. The aim of this paper is: 1. modeling the growth of tumor spheroids; 2 . simulating different clinical treatment schedules applied to irradiation of in-vitro tumor spheroids; 3 . considering the side effects on normal tissue. A comparison of the simulation results with clinical experience demonstrates that the clinical reality can qualitatively be represented by the model. This method enables a reduction of timeconsuming studies prior to clinical therapy.
\end{abstract}

\section{Keywords}

Cancer, computer simulation, fractionation, modeling, radiation therapy, side effects, tumor growth

\section{INTRODUCTION}

Our research group is intensively involved in the modeling of malignant and normal cell growth and applies methods of control theory. This approach and other aspects have brought about the hypothesis to associate tumor growth with a cellular division control circuit which has become structure-unstable. The scope of these investigations was to stepwise develop numerous models for the description of the chronological and spatial growth of tumors and of the time behavior of normal cell renewal systems (Düchting, 1990). The growth models were extended 
by a radiobiological dose-response model based on the linear-quadratic approach (Fowler, 1989). Thus, clinical irradiation schemes can be tested by computer experiments at in-vitro tumor spheroids and at normal cells providing a contribution to the optimization of therapy planning.

\section{CELL GROWTH AND RENEWAL MODELS}

Based on a control model which describes the cell division of a tumor cell (Figure 1) with cellkinetic data and on cell production and interaction rules, we constructed a model simulating the growth of a tumor spheroid (Düchting, 1990) with a steady state volume of about $1 \mathrm{~mm}^{3}$. If we want to study the radiation side effects produced in normal cells of the target as well, we additionally have to model the renewal of rapidly proliferating cell systems (Figure 2) which are comprising a stem-cell compartment (Düchting et al., 1994), and the renewal of slowly proliferating parenchymal tissue (Figure 3) which mainly consists of a pool of indivisible resting G0-cells (Düchting et al., 1995).

\section{IRRADIATION MODEL}

In order to construct a model describing radiation treatment, it is necessary to know the number of cells hit by radiation. The computation of the percentage of the cells killed by irradiation is based on the ,linear-quadratic model“" (Fowler, 1989) with the survival function:

$$
\mathrm{S}(\mathrm{D})=\mathrm{e}^{-\alpha \mathrm{D}} * \mathrm{e}^{-\beta \mathrm{D}^{2}}
$$

In equation 1, D stands for dose, and $\alpha, \beta$ are symbolizing parameters depending on the kind of cells and on the type of radiation. The number of the cells to be killed can be determined via equation 1. Subsequently, the killing is performed by means of pseudo-random-number generators in the computer model. To become more realistic, the simplified model was enriched by implementing the following additional considerations: repair mechanisms, reoxygenation, lysis, dose-dependent parameters (Düchting et al., 1992, 1994, 1995).

\section{SIMULATION OF FRACTIONATED RADIATION THERAPY}

It is well known in radiobiology and radiotherapy that, contrary to a single tumor irradiation, a fractionated application offers many advantages. Going into further detail, advanced results of radiobiology provide many rationales for modifications of the daily applied irradiation dose of $1 \times 2$ Gy (standard fractionation scheme, $D_{\text {TOTAL }}=60 \mathrm{~Gy}$ ) usually found in clinical routine. Thus, the task was to develop a treatment scheme which leads to a maximum cell kill of tumor cells and to a minimum damage of normal cells. Because of the complexity and heterogenity of biological systems, we started with very simple simulation experiments to study clinical treatment schedules applied to in-vitro tumor growth and to normal tissue under different assumptions and restrictions. The simulation experiments were performed on a DEC 3000 Model 400 AXP workstation. The computing time takes about 40 minutes for simulating a 


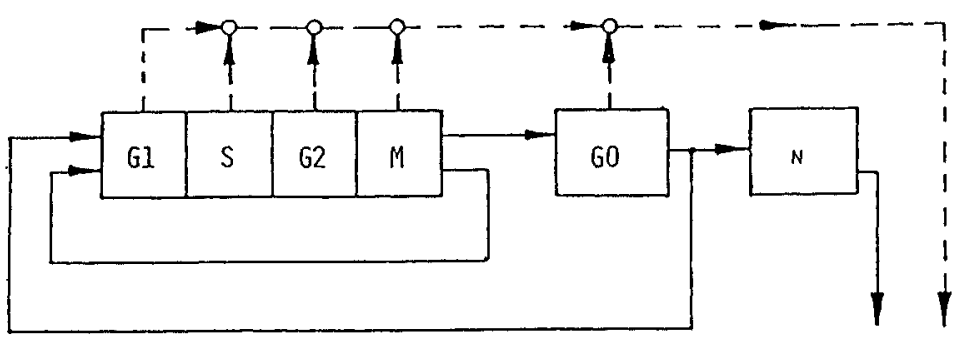

CELL DEATH

Figure 1 Simplified cytokinetic model of a tumor cell (G1, S, G2, M: Cell cycle phases; Go: Resting phase; N: Necrotic state).

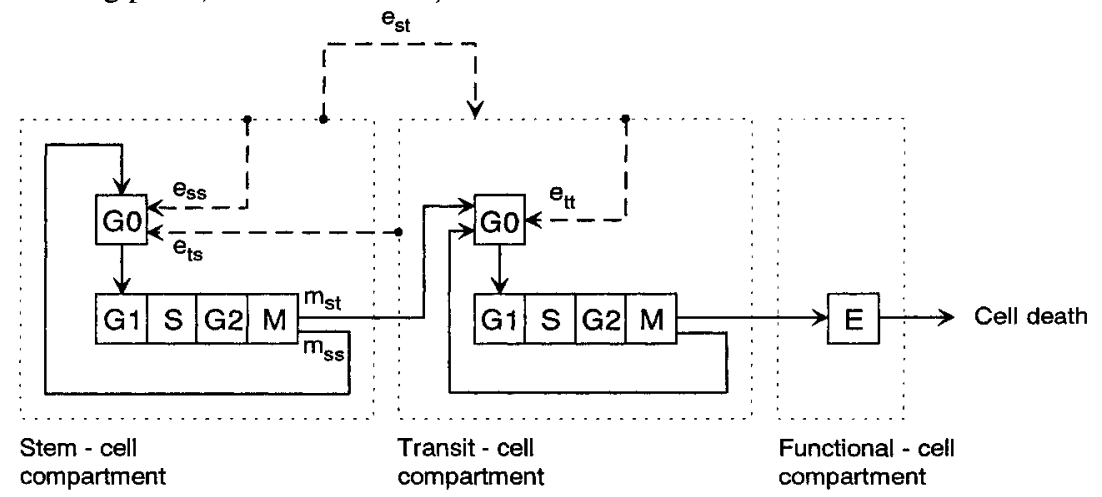

Figure 2 Cellkinetic model of radpidly renewing normal tissue $\left(m_{s s}, m_{s t}, e_{s s}, e_{t s}, e_{t t}\right.$, $e_{s t}$ : Control and regulation variables, see Düchting et al., 1994).

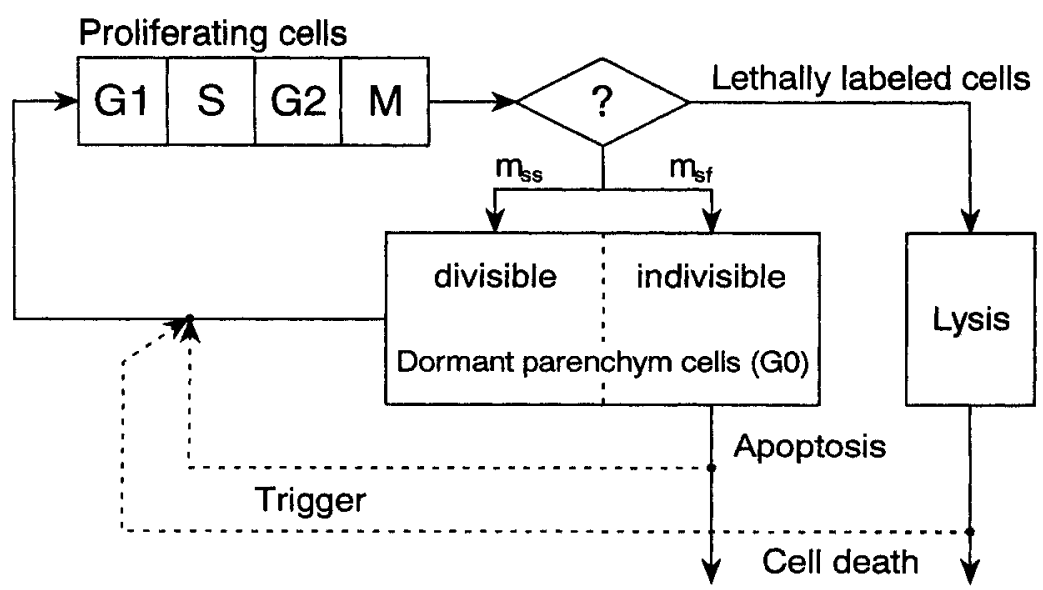

Figure 3 Cellkinetic model of slowly renewing normal tissue (parenchym; $m_{s s}, m_{s f}$. Control and regulation variables, see Düchting et al., 1995). 
single therapy course of about 60 days. In the following sections five different fractionation schemes (Table 1) are simulated for different growing cell systems.

Table 1 Different fractionation schemes

\begin{tabular}{lll}
\hline Fractionation schemes & \multicolumn{1}{c}{ Dose (Gy) } \\
\hline Standardfractionation & 1 & $1 \times 2$ Gy per day \\
Superfractionation & 2 & $\begin{array}{l}3 \text { single doses per day in an interval of } 4 \mathrm{~h}: \\
0.7 / 0.6 / 0.7 \mathrm{~Gy}\end{array}$ \\
Hyperfractionation I & 3 & $\begin{array}{l}3 \text { single doses per day in an interval of } 4 \mathrm{~h} \text { : } \\
1 / 1 / 1 \mathrm{~Gy}\end{array}$ \\
Hyperfractionation II & 4 & $\begin{array}{l}3 \text { single doses per day in an interval of } 4 \mathrm{~h} \text { : } \\
1.5 / 1.5 / 1.5 \mathrm{~Gy}\end{array}$ \\
Weekly high single dose & 5 & $1 \times 6$ Gy per week \\
\hline
\end{tabular}

\subsection{Irradiation of a rapidly growing tumor spheroid}

The constructed computer model (Düchting, 1990) based on Figure 1 allows the calculation and representation of the spatial configuration and of the time behavior of the irradiated tumor spheroid. To demonstrate the power of the model, Figure 4 shows the spatial configuration of the hyperfractionated irradiation (scheme 4, Table 1) of a moderately fast growing tumor spheroid (e.g. squamous carcinoma of the lung) at three different points of time starting at $t=500$ hours after first dose application. The time course of the number of tumor cells of an irradiated small cell lung carcinoma spheroid is plotted with five different fractionation schemes in Figure 5 (data see Düchting, 1992).

\subsection{Irradiation of rapidly renewing normal tissue}

In radiation therapy of malignant tumors normal cells are inevitably exposed to ionizing rays, and therefore the effectivity of tumor destruction of a therapy regimen and the associated sideeffects produced in normal cells of the target have to be balanced up. The clinical and radiobiological experiences have shown that the irradiation of normal cells has to imply both acute and late effects. Acute effects can already be observed a few days after the corresponding radiation exposition, whereas late responses may be registered after a latency period of 6-12 months. It was clinically verified that acute responses preferrably occur in rapidly renewing tissues (epidermis, mucosa, skin) and radiogenic late effects are preferrably observed in slowly renewing kinds of tissue (e.g. parenchym, connective tissue). 

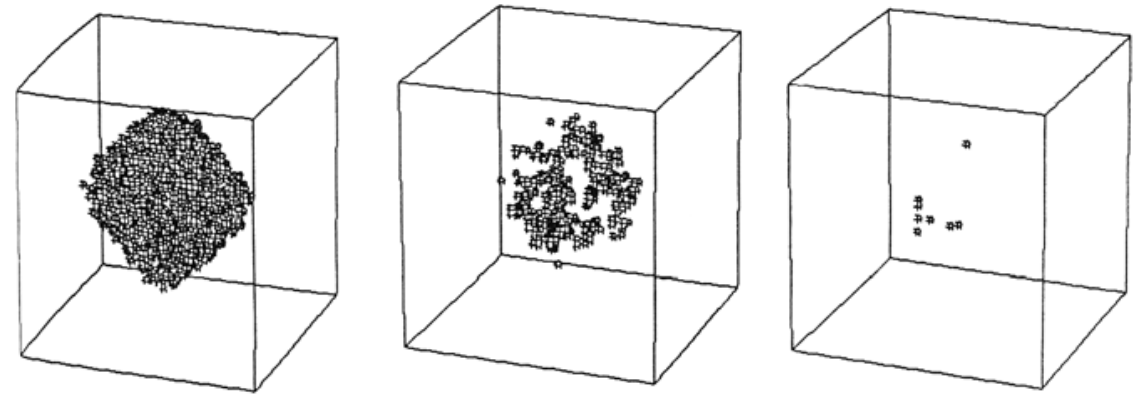

$t_{1}=506 h$

$t_{2}=686 h$

$t_{3}=866 h$

Figure 4 3D illustration of a hyperfractionated irradiation (scheme 3 , see Table 1) of a moderately fast growing tumor spheroid (e.g. squamous carcinoma of the lung) in a nutrient medium.

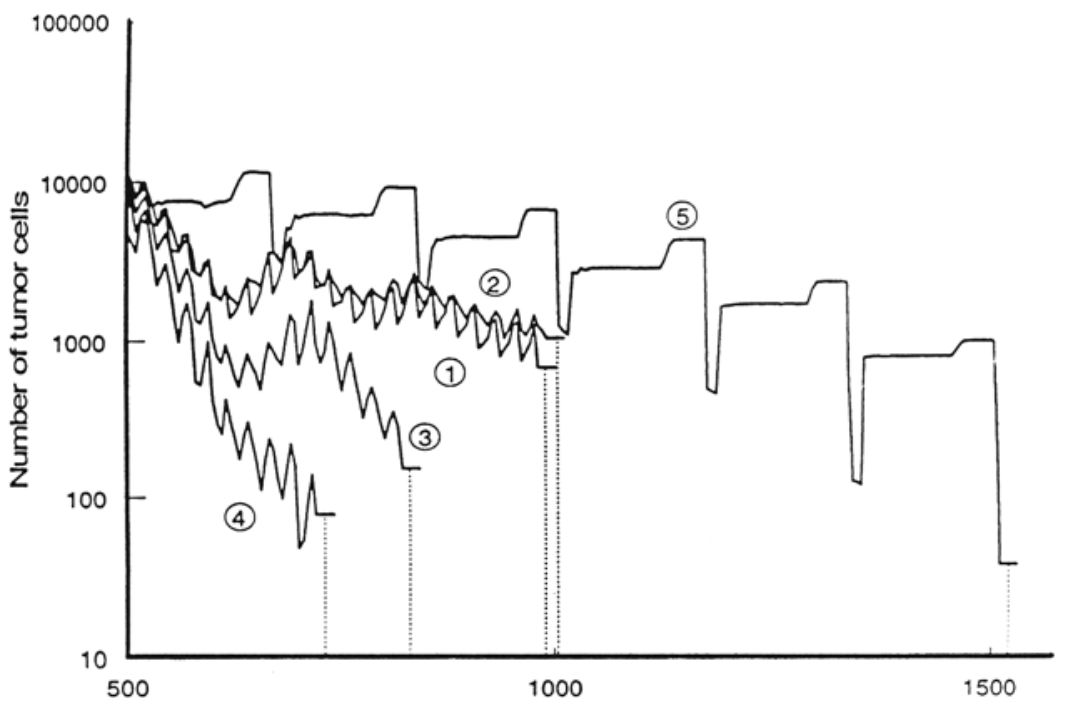

Figure 5 Irradiation of a rapidly growing tumor spheroid (e.g. small cell lung carcinoma) with 5 different fractionation schemes (Table 1; the dotted line indicates the upper limit of dose D $\mathrm{D}_{\mathrm{TOTAL}}=60 \mathrm{~Gy}$ ). 
Based on the computer model (Figure 2) describing the dynamics of rapidly proliferating normal tissue (Düchting et al., 1994), Figure 6 represents the simulation run of the radiogenic response of the thin epidermis of the mouse induced by different fractionation schemes (Table 1).

\subsection{Irradiation of slowly renewing normal tissue}

Late effects appear after a typical latency period of approx. 3-6 months (or sometimes longer) and preferrably occur in slowly renewing normal tissue, e.g. parenchym (brain, lung), connective tissue. While rapidly proliferating cell systems consist of hierarchically structured compartments (stem -, transit -, fiunctional cell compartment), parenchymal tissue contains highly differentiated functional cells residing in the resting phase G0 (Figure 3). The cell space of our computer model is only about $1 \mathrm{~mm}^{3}$ which implies about 74.000 cells. Therefore, it is tolerated to assume a sufficient nutrient supply of all cells and to neglect an explicite representation of the capillary network. Based on the computer model (Figure 3) describing the dynamics of slowly renewing normal tissue (Düchting et al., 1995), the simulation result in Figure 7 represents the radiogenic response of the brain parenchym of the mouse induced by different fractionation schemes (Table 1).

\section{DISCUSSION}

Every fractionation scheme can only be evaluated by a juxtaposition of its tumor kill effectivity and severity of side effects in normal tissue. In Figure 5 we have presented a computer simulation result of fractionated radiation therapy applied to a tumor spheroid of a small cell lung carcinoma. A comparison with the results of Figure 6 referring to the same treatment schemes indicates that hyperfractionation II (scheme 4, Table 1) implies the highest tumor cell kill, but also severe acute responses of the thin epidermis of the mouse. Since repopulation in the irradiated target can hardly be expected, this scheme can only be taken into account, if the irradiated areas can be kept small or else the overall dose should be reduced.

Comparing the results of Figure 7 to those of Figures 5 and 6, hyperfractionation II (scheme 4, Table 1) tends in every case to produce severe radiation responses. On the other side, this schedule may be correlated with the most significant tumor kill effectivity. Therefore, the adequacy of this therapy modality is only ensured, if the tumor volume and the associated volume of normal tissue are small in order to prevent severe late and acute side-effects in an extended area. A further possibility is a reduction of the overall dose, e. g. DTOTAL $=50 \mathrm{~Gy}$ instead of $60 \mathrm{~Gy}$, as considered by some authors.

A difficult problem is the evaluation of scheme 5 (weekly high single dose, scheme 5 , Table 1). Since the superior tumor kill effect of scheme 5 in Figure 5 could not be verified by some other authors, the more significant acute and late effects produced by scheme 5 (Figures 6 to 7) should be kept in view.

However, the presented computer simulation models may serve as additional tools for the therapists. On the basis of the experiences of the already published results, our group is paying much effort to develop improved simulation models. 


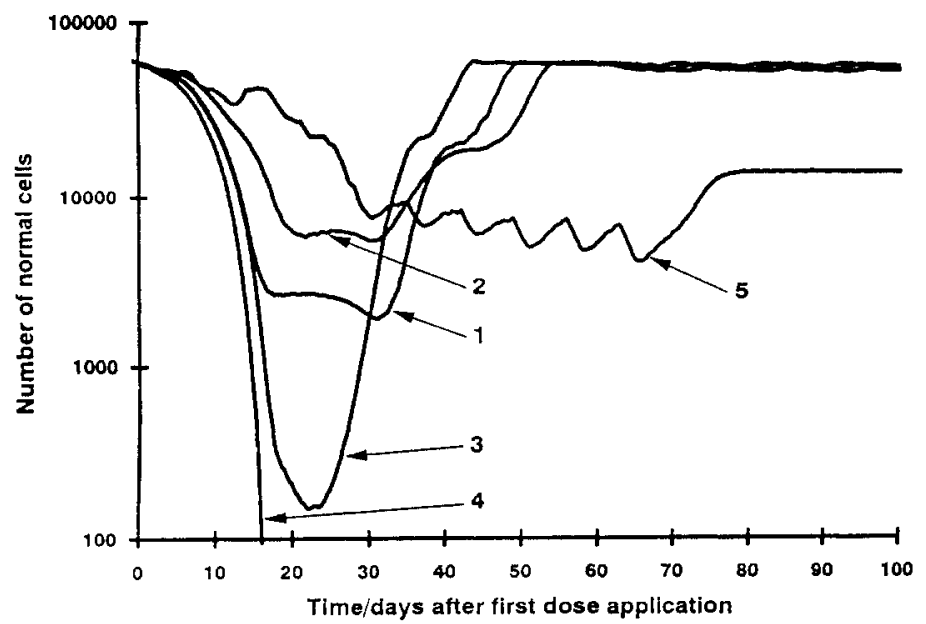

Figure 6 Irradiation of the thin epidermis of the mouse with 5 different fractionation schemes (see Table 1).

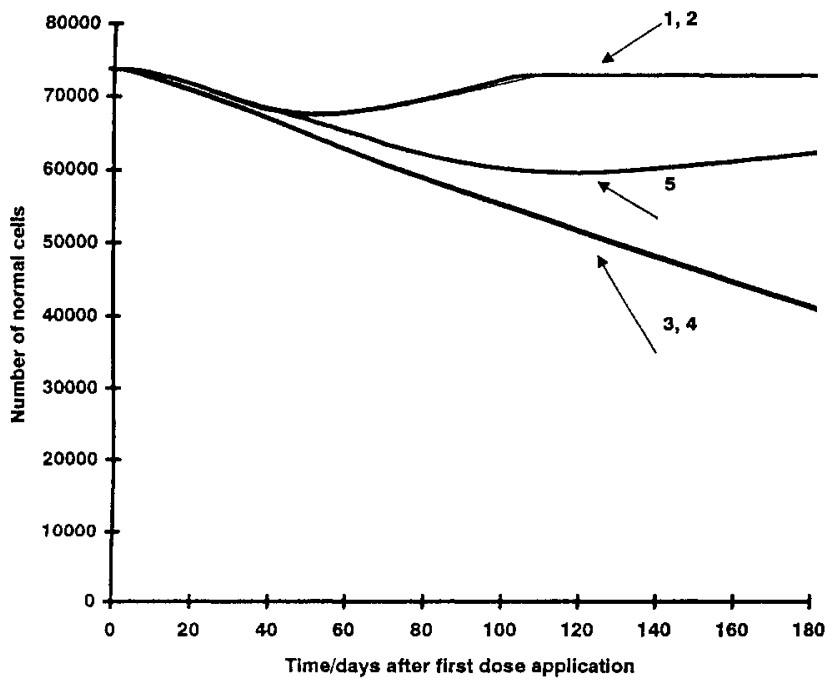

Figure 7 Irradiation of the brain parenchym of the mouse with 5 different fractionation schemes (see Table 1). 


\section{REFERENCES}

Düchting, W. (1990) Computer simulation in cancer research, in Advanced Simulation in Biomedicine (ed. D.P.F. Möller), Springer, New York, 117-139.

Düchting, W., Ulmer, W., Lehrig, R., Ginsberg, T., and Dedeleit, E. (1992) Computer simulation and modelling of tumor spheroid growth and their relevance for optimization of fractionated radiotherapy. Strahlenther. Onkol., 168, 354-360.

Düchting, W., Ulmer, W., Ginsberg, T., and Saile, C. (1994) Radiogenic responses of normal tissue induced by fractionated irradiation - a simulation study. I Acute responses (submitted to publication).

Düchting, W., Ulmer, W., Ginsberg, T., Kikhounga-N'Got, O., and Saile, C. (1995)

Radiogenic responses of normal tissue induced by fractionated irradiation - a simulation study. II Late responses. Strahlenther. Onkol. (in press).

Fowler, J.F. (1989) The linear-quadratic formula and progress in fractionated radiotherapy. Brit. J. Radiol., 62, 679-694. 